\title{
Trade Conflicts and China's Macroeconomic Fluctuations --- An Empirical Analysis Based on Vector Autoregression Model
}

\author{
Chenggang $\mathrm{Li}^{1,2}$, Yong Gan ${ }^{1, a}$ \\ ${ }^{1}$ Faculty of Big Data Statistics and Economics, Guizhou University of Finance and Economics, Guiyang 550025, China \\ ${ }^{2}$ New Structural Financial Research Center, Guizhou University of Finance and Economics, Guiyang 550025, China
}

\begin{abstract}
This paper uses the data from November 2016 to June 2018 to construct a VAR model to empirically analyze the impact of trade wars on the Chinese economy since the trade friction between China and the United States. The empirical results show that the trade conflict between China and the United States will have short-term effects on financial institution loans, net export fluctuations, capital markets, short-term international capital flows, and the RMB exchange rate. After the impact of the trade war, the Chinese economy will have a spontaneous adjustment function, which will cause a certain positive and negative change in economic changes. But over time, the impact of Sino-US trade conflicts on financial institution loans, net export volatility, asset prices, short-term international capital flows, and the RMB exchange rate has gradually weakened until the gradual convergence to the zero axis and the effect disappears.
\end{abstract}

Keywords: Trade conflict; Macroeconomy; Vector autoregression model; Impulse response

\section{Introduction}

In 2016, China's exports to the United States accounted for $18 \%$ of China's total merchandise exports and $4.4 \%$ of GDP. In 2017, Sino-US trade total 3.95 trillion yuan, accounting for $14.2 \%$ of China's total import and export volume. For a long time, the United States has been China's largest trade exporter and the largest source of trade surplus. If Sino-US trade relations go bad, it will be difficult for China to find an alternative market for the US market in a short period of time. At the same time, with the rise of the Trump administration's national protectionism, Sino-US trade frictions continue. In January 2018, the Trump administration announced a tariff of up to $30 \%$ and $50 \%$ on imported large washing machines and photovoltaic products. On July 6, 2018, the United States began to impose a $25 \%$ import tariff on Chinese goods valued at $\$ 34$ billion. Facing the US's important trading partner status with China and the escalating trade friction. Studying the impact of trade wars on the Chinese economy and discussing possible viable policies have been important to an imminent level.

Some scholars have studied the causes of trade wars. Gene considered trade agreements to be the equilibrium result of the bargaining game model between the two governments. Langdon and Bown argue that trade friction is not regular, there is trade friction in the existence of international trade, and the greater the trade scale, the greater trade friction. D Xie and G Zhang (2018)[1] SinoUS trade friction is the product of the contradictions between the economic interests of China and the United
States, and can only be gradually resolved in the debugging of mutual economic interests. LJ Huang (2018) [2] attributed the cause of the trade war to the rise of American populism and the containment of China's rise.

There are also scholars studying the impact of trade wars. R Wu and HY Liu(2009)[3] used the trade war model to study the balanced import and export policy implemented by the major powers in intra-industry trade under the monopolistic competition. The conclusions show that the enhancement of product competitiveness will unilaterally increase the scale of trade wars. F Yang and W Sun(2018)[4] through the counting model, using the 2000-2014 WIOD and anti-dumping data to empirically test that the United States is credible for strategic considerations to curb the development of China's high-tech industry. In the trade war, the US government will intervene in the normal operation of Chinese companies in the United States in different ways, thus seriously affecting the investment of Chinese companies in the United States (Schmidt, 2004)[5].

The current scholars' research is mainly based on the qualitative study of basic facts and the reasons or influences and development of trade wars. The scholars' research at the economic analysis level is devoted to constructing the dynamic balance of trade volume changes and exchange rate changes on China's macroeconomic impact. Few scholars have focused their attention on the study of dynamic impact processes. The main innovation of this paper is to set trade conflicts into time-series into virtual variables to act on various indicators of China's macro-economy, making abstract

a253378633@qq.com 
trade warfare into measurable and tangible data, and introducing VAR model into trade conflict analysis system.

\section{Variable selection and data source}

Trade conflict (CONFI). On the basis of full consideration of scientific, measurable principles, and reliability principles, dummy variables are selected as proxy variables for measuring trade conflicts. If one or both of the United States or China announces tariffs in the month, the month is set to 1 , otherwise 0 .

Financial institution loan $(L O A N)$. The increase in the growth rate of credit is one of the most important indicators for measuring financial institution loans. Financial institution loans directly affect the size of M2, and M2 is significantly related to GDP and CPI.

Net export fluctuations (NETEX). The net export growth rate is the sequential growth rate. One of the most important parts of the trade war is that the United States has substantially increased tariffs on China. If the United States illegally increases tariffs, our economy is the first to bear the trade volume of the United States.

Capital market (ASSET). The Shanghai Composite Index has a sequential growth rate. Using the ring growth rate of the Shanghai Composite Index to measure the strong representativeness of China's asset price fluctuations, and its strong liquidity and measurability are not comparable to other indicators.

Short-term international capital $(C A P)$. Actually use the foreign direct investment amount to increase the growth rate. We choose the monthly growth rate of the actual use of foreign investment to measure the flow of short-term international capital in our country.

RMB exchange rate (ERATE). The growth rate of the US dollar against the RMB exchange rate. The exchange rate and import and export are a pair of related variables. The total foreign exchange accumulated by the trade surplus will put pressure on the RMB to appreciate. Similarly, the depreciation of the RMB can promote exports.

This paper selects the data from May 2017 to August 2018. The data mainly comes from the statistics of the General Administration of Customs, the WIND database, the People's Bank of China, the RESSET database and the National Bureau of Statistics of China.

\section{Data inspection and model setting}

\subsection{Data stationarity test}

In this paper, the unit root test is performed on each indicator by using the ADF method. The presence or absence of drift terms and trend terms is determined based on the timing diagrams of the variables, and the lag order is determined based on the AIC and SC information criteria. At a significance level of 0.05 , the six sequences were stable over a $95 \%$ confidence interval. Therefore, the test results show that the data is stable and in accordance with the conditions for constructing the VAR model.

\subsection{Construction of vector autoregression (VAR) model}

VAR model general mathematical expression:

$$
Y_{t}=M_{1} Y_{t-1}+M_{2} Y_{t-2}+\ldots \ldots+M_{p} Y_{t-p}+N_{1} X_{t} \ldots \ldots+N_{t-r}+\varepsilon_{t}
$$

$Y_{t}$ is a k-dimensional endogenous variable column vector. $X_{t}$ is a d-dimensional exogenous variable vector, $P$ is the lag order of endogenous variables. $t$ is the lag order of the exogenous variable. $\varepsilon_{t}$ is a k-dimensional random perturbation column vector.

Gao(20016)[6] pointed out that the traditional VAR theory requires that each variable in the model is stable, and the data in this paper has passed the unit root test, so the VAR model can be directly established. As shown in Table 1, 3 of the 5 indicators determine that the lag phase 2 is the optimal lag period. Therefore, a vector autoregressive model with lag phase $2 \operatorname{VAR}(2)$ model, is established.

Table 1. VAR Lag Order Selection Criteria

\begin{tabular}{|c|c|c|c|c|c|c|}
\hline Lag & LogL & LR & FPE & AIC & SC & HQ \\
\hline 0.00 & 68.27 & NA & 0.00 & -5.93 & $-5.63 *$ & -5.87 \\
\hline 1.00 & 114.97 & $62.27 *$ & 0.00 & -6.95 & -4.86 & -6.50 \\
\hline 2.00 & 175.88 & 46.41 & $1.26 *$ & $-9.32 *$ & -5.44 & $-8.47 *$ \\
\hline
\end{tabular}

Note: * indicates the hysteresis order selected by the standard. LR: sequentially modified LR test statistic (each test is at 5\% level). FPE: final prediction error. AIC: Akaike information standard. SC: Schwarz information standard. HQ: Hannan-Quinn information standard.

\section{Impulse response analysis}

For the established VAR(2) model, the stability of the AR root must be verified to ensure the validity of the impulse response function results. there is no eigenvalue outside the unit circle, and the established VAR model satisfies the stable condition. Subsequent impulse responses will be based on a stable VAR model. The VAR model is a non-theoretical model that uses an impulse response function to analyze the effect of a standard deviation of a random disturbance on the endogenous variable, how the influence of the disturbance term is propagated to each variable. The horizontal axis of the impulse response diagram indicates the number of lag periods of the impact (unit: month). In order to keep consistent with the time interval, the lag interval is set to 23 months, the solid line indicates the impulse response function, and the broken line indicates the positive and negative twice the standard deviation deviation band.

Figure 1 shows the impulse response of NASSEP to $C O N F I$. It can be seen from figure 2 that after a shock to CONFI in this period, the NASSEP will have a negative effect in the early stage, but this negative effect will 
continue to weaken over time, and then gradually converge to zero, and finally the effect disappears. When the trade war occurred with the performance of export enterprises greatly damaged, and part of the capital outflow, the initial impact of the trade war will show a negative impact on the Shanghai Composite Index, that is, the negative reaction of asset prices. However, the impact of this shock on the Chinese stock market is definitely not permanent, but will gradually weaken over time to mean that the impact fades to zero.

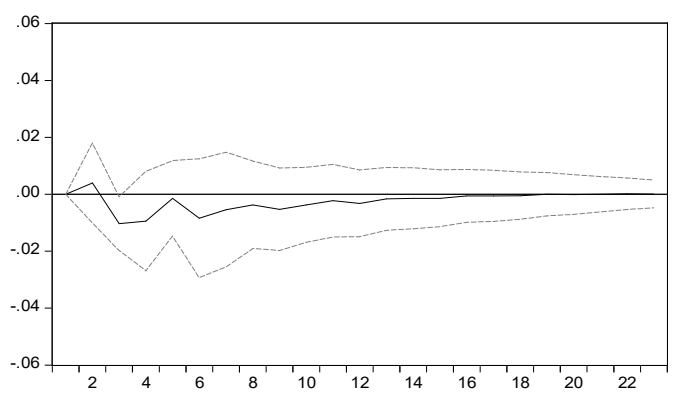

Figure 1. Response of NASSEP to CONFI

Figure 2 shows the impulse response of ERATE to CONFI. As can be seen from figure 3, after a shock to $C O N F I$ in this period, the early stage will have a positive effect on ERATE, but this positive effect will continue to weaken over time, then gradually converge to zero, and finally the effect disappears. The exchange rate of this article adopts the direct price method, and the positive reaction represents the rise of the dollar against the Renminbi, that is, the devaluation of the Renminbi. After the trade war, China's exports to the United States fell sharply in the short term, the trade surplus with the United States decreased, and the growth rate of foreign exchange reserves declined, which in turn affected the foreign exchange market, forcing the yuan to depreciate. The devaluation of the Renminbi triggered an automatic adjustment mechanism that played a role in China's exports and entered a new balance.

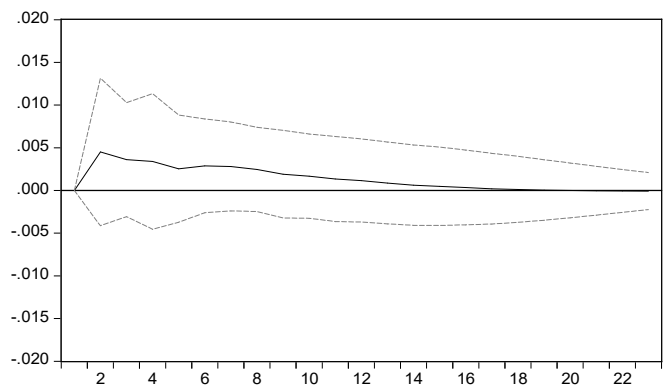

Figure 2. Response of ERATE to CONFI

Figure 3 shows the impulse response of NETEX to $C O N F I$. It can be seen from figure 4 that after a shock to CONFI in this period, the NETEX will have periodic positive and negative alternating effects in the early stage, and the positive and negative effects will gradually weaken with time, and then gradually converge to zero, and the influence disappears. The U.S. government unilaterally took the lead in increasing tariffs on China, which first caused a negative impact on China's exports.
The U.S. exports to China increased relatively. With the accumulation of trade surplus, U.S. foreign exchange reserves increased, the Renminbi appreciated against the U.S. dollar, and exports decreased. It is periodically adjusted to form a new balance.

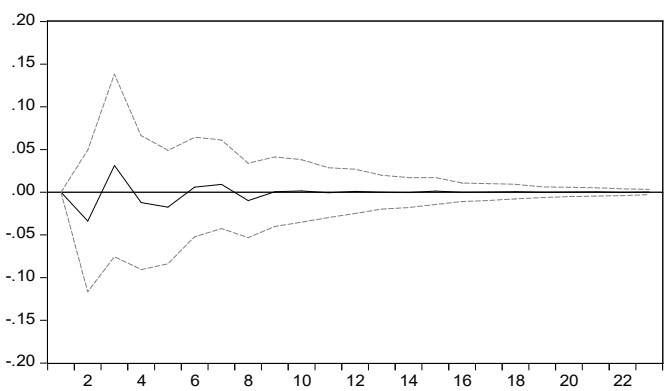

Figure 3. Response of NETEX to CONFI

Figure 4 shows the impulse response of $L O A N$ to CONFI. It can be seen from Fig. 5 that after a shock to $C O N F I$ in this period, the $L O A N$ will have a cyclical positive reaction in the early stage, and then reach a peak and then weaken to zero, and then periodically change with the decrease of the amplitude, gradually converge to zero and the effect disappears. After the trade war, the Chinese government adopted an expansionary fiscal policy to stabilize economic growth and a number of RRR cuts to release liquidity. Therefore, the amount of credit will increase in the short term. However, after the increase to the peak, the spontaneous adjustment mechanism came into effect, and the credit growth rate showed a slowing trend. This is then repeated until the effect of the impact is digested, and the corresponding pulse corresponding map converges to the zero axis.

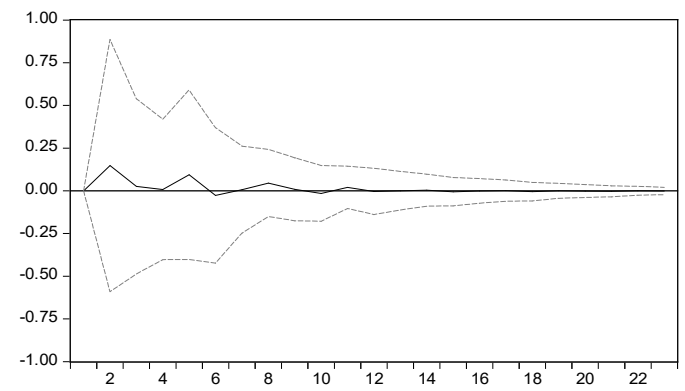

Figure 4. Response of $L O A N$ to $C O N F I$

Figure 5 shows the impulse response of $C A P$ to $C O N F I$. It can be seen from figure 5 that after a shock to $C O N F I$ in this period, the $C A P$ will have cyclical positive and negative alternate effects in the early stage, and the growth rate of China's direct use of foreign capital will be negatively affected by the foreign risk aversion. However, when the negative impact of the FDI growth rate peaks, this negative impact gradually weakens until it gradually develops. As the peak decreases, this effect changes periodically, eventually converges to the zero axis and the effect disappears. 


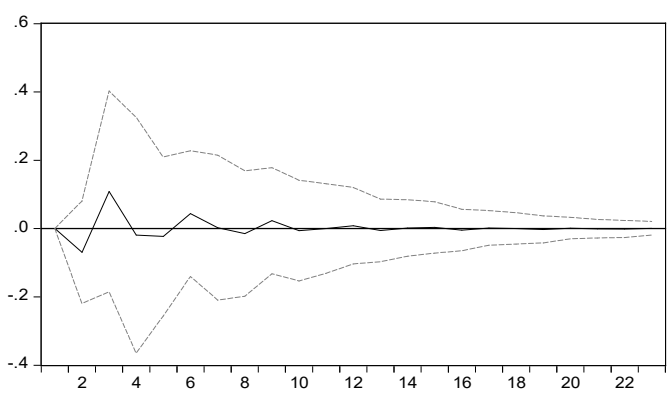

Figure 5. Response of $C A P$ to $C O N F I$

\section{Conclusions}

This paper uses the data from October 2016 to August 2018 to construct a VAR model, and analyzes the impact of trade war on financial institution loans, net export fluctuations, asset prices, short-term international capital flows, and RMB exchange rate through an impulse response function. The research results show that: (1) Sino-US trade conflict will have an impact on China's red macro economy in the short term. (2) After the impact of the trade war, the Chinese economy will have a spontaneous adjustment function, which will cause a certain positive and negative change in economic changes. (3) In the long run, the impact of trade wars on various aspects of China's economy will gradually weaken over time and finally enter a new equilibrium.

\section{Acknowledgement}

This paper is supported by the General Projects of the National Social Science Fund (17BJY021) of National Planning Office for Philosophy and Social Sciences: Research on the structural reform path of supply-side of the tea industry in China under the background of "One belt and One road".

\section{References}

1. D. Xie, F Zhang. The Political Economic Analysis of Trade Frictions between China and the United States. J. China Review of Political Economy, 9(2018): 121-143.

2. L.J. Huang. The Cause, Influence and Trend Analysis of the Upgrading of Sino-US Trade War. J. New Finance, 9(2018): 20-24.

3. R.Q. Wu, H.Y. Liu. Monopolistic Competition, Interest Groups and Trade Wars. J. China Economic Quarterly, 8(2009):829-848.

4. F. Yang, W.Y. Sun, Y. Cheng. Does Technology CatchingUp Inspire Sino-U.S. Trade Friction. J. China Industrial Economics, 10(2018): 99-117.

F. Yang, W.Y. Sun, Y. Cheng. Does Technology CatchingUp Inspire Sino-U.S. Trade Friction. J. China Industrial Economics, 10(2018): 99-117.

5. D. P. Schmidt, Intellectual Property Battles in a Technological Global Economy. J. War Analysis Business Ethics Quarterly, 14(2004): 679-693.

6. T.M. Gao. Econometric methods and modeling. M. Beijing: Tsinghua University Press, (2016): 329-385. 